\title{
A multi-field bio-economic model of irrigated grain-cotton farming systems
}

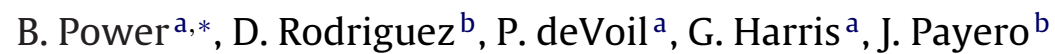 \\ a Agri-Science Queensland, Department of Employment, Economic Development E Innovation (DEEDI), PO Box 102, Toowoomba, Queensland 4350, Australia \\ ${ }^{\mathrm{b}}$ Queensland Alliance for Agriculture and Food Innovation (QAAFI), University of Queensland, Brisbane, Australia
}

\section{A R T I C L E I N F O}

\section{Article history:}

Received 15 October 2010

Accepted 29 March 2011

\section{Keywords:}

APSIM

Whole farm resource allocation

Farming systems design

\begin{abstract}
A B S T R A C T
We present a participatory modelling framework that integrates information from interviews and discussions with farmers and consultants, with dynamic bio-economic models to answer complex questions on the allocation of limited resources at the farm business level. Interviews and discussions with farmers were used to: describe the farm business; identify relevant research questions; identify potential solutions; and discuss and learn from the whole-farm simulations. The simulations are done using a whole-farm, multi-field configuration of APSIM (APSFarm). APSFarm results were validated against farmers' experience. Once the model was accepted by the participating farmers as a fair representation of their farm business, the model was used to explore changes in the tactical or strategic management of the farm and results were then discussed to identify feasible options for improvement.

Here we describe the modelling framework and present an example of the application of integrative whole farm system tools to answer relevant questions from an irrigated farm business case study near Dalby (151.27E - 27.17S), Queensland, Australia. Results indicated that even though cotton crops generates more farm income per hectare a more diversified rotation with less cotton would be relatively more profitable, with no increase in risk, as a more cotton dominated traditional rotation. Results are discussed in terms of the benefits and constraints from developing and applying more integrative approaches to represent farm businesses and their management in participatory research projects with the aim of designing more profitable and sustainable irrigated farming systems.
\end{abstract}

Crown Copyright (c) 2011 Published by Elsevier B.V. All rights reserved.

\section{Introduction}

The pressure to increase food and fibre production driven by world population growth, qualitative shifts in food demand and expected changes in climate, are likely to exacerbate trade-offs between profit and risk, and between economic and environmental outputs in agricultural production systems (Parry et al., 2009). The magnitude of the challenge is such that identifying feasible adaptation options, short term tactics and medium to long term plans and strategies is unlikely to emerge from single disciplinary science (Howden et al., 2007; Meinke et al., 2009). Here we argue that this challenge will require the development of more integrative, inter disciplinary systems solutions, involving all the required actors (i.e. researchers, modellers, practitioners, private consultants, agribusinesses, advocacy groups, etc.) i.e. from the description of the problem to the identification of actionable solutions (Meinke et al., 2009). A key argument for this is that farmers manage complex farm businesses in highly variable and uncertain operating environments, managing limited amounts of resources

\footnotetext{
* Corresponding author. Tel.: +61 746881624.

E-mail address: brendan.power@deedi.qld.gov.au (B. Power).
}

(including time and knowledge), to satisfy multiple objectives and having particular risk preferences.

A good example of the challenges ahead in the development and application of integrative and interdisciplinary sciences lies in the Australian broad acre irrigated cropping industry. Australian irrigators are under increasing pressure to maintain the viability of their farm business due to: reduced allocations of surface and underground water; increasing competition from alternative users (such as urban, industry and the environment); the cost-price squeeze; and the threat of climate change. Clearly these will not be solved through the isolated efforts of breeding, agronomy, soil sciences, or agricultural economics, but most likely by a concerted effort in which systems analysis and modelling can play a fundamental role.

Irrigated grain-cotton farmers from Queensland continuously adapt their management practices in response to changes in their operational environment, though it is recognised that medium and long term farm business planning requires greater levels of information and support to ensure success. Desktop studies have long been used in the analysis of cropping systems to: explore the optimal allocation of limiting resources in farming systems (Tittonell et al., 2007); assist farmers in understanding and managing complicated farming systems (McCown et al., 2009); quantify impacts and identify adaptation options to climate variability and change 
(Reyenga et al., 1999; Howden et al., 2007); as an aid in decision making or as discussion support tools (Meinke and Hochman, 2000; McCown, 2002; Nelson et al., 2002).

In many cases, such desktop studies have involved the development and application of either whole-farm dynamic equilibrium models (Kingwell and Pannell, 1987) or point-scale bio-economic models together with a scaling up to the whole farm level (Brennan et al., 2008). However, static-equilibrium models are limited in their applicability due to a reliance on assumptions made $a$ priori about likely yields, prices, water allocations, etc.; and their inability to dynamically account for tactical and strategic responses to seasonal changes in climate and markets. Dillon (1965) described their application to farm management as "logically attractive but largely inapplicable theory". However he conceded their suitability when modelling regional implications for policy. McCown and Parton (2006) argued that static equilibrium models fail when applied in the analysis of farm management because farms are: unique, dynamic, complex, exist in an uncertain environment, and farmers each have different preferences.

Here we present APSFarm, a dynamic modelling framework that integrates multiple bio-physical models that operate at the management unit, the farm and the sub-catchment. We argue that APSFarm can adequately model the dynamics and key meaningful interactions in real farms, addressing all or most factors raised by McCown and Parton (2006), and there-by creating a more realistic virtual representation of the hurdles farmers undergo when managing their farms. In this paper we (i) describe the development of APSFarm to simulate irrigated grain-cotton cropping systems; and (ii) report on the results from its application in a participatory research project where the model was used to compare two alternative crop rotations from a case study farm located near Dalby, Queensland, Australia.

\section{Methods}

\subsection{Description of the modelling framework}

When developing economic and bio-physical models of farms a three-way trade off exists between generalisations so that conclusion and inferences may be made about other farms of similar type, a simplification of reality, and model complexity so that the model adequately represents the dynamics of the farm production system. The extension of APSIM (Keating et al., 2003) to APSFarm is described in de Voil et al. (2009) which describes three components of the extension: multiple fields, farm level resources and management, and a module for economic analysis. Here we describe these three components in an irrigated farming systems context.

\subsubsection{Description of model cropping area and its management}

APSFarm is a multi-field configuration of the APSIM model, i.e. a collection of fields (or management units), each potentially having different soil parameters, cropping history, area, or management. For simplicity, here the area of each simulated field was constrained to the area that the existing farm infrastructure can irrigate in one day. The management of these fields is achieved via a "farm level manager" that accounts for two types of decisions, tactical and strategic, each with its own operational scope. We consider tactical those short term seasonal decisions that are specific to particular fields, e.g. fertiliser rates, sowing densities and irrigation management. Strategic management decisions relate to operations affecting or being informed by the availability of resources at the whole farm level, e.g. implementing crop rotations, setting priorities for irrigating alternative crops, and the on farm movement of water between storages so that irrigation supply costs and water losses due to evaporation and drainage are minimised.
The decision of what crop to sow each season in each field is determined by pre-specified rules and actions associated with the arcs and nodes of a directed graph (see Fig. 1 for an example implementation). The nodes of the graph represent the states in which the field can be found at any point in time, e.g. a specific crop or Fallow for no crop. The arcs between nodes hold the description of rules in the form of Boolean expressions and actions that a farmer would perform on each field such as sow or harvest a crop. When the rules are evaluated to true they allow the transition between different states to occur and the actions are taken. The model has a daily time step and hence these rules are evaluated every day of the simulation for each field.

To illustrate consider the example of a crop rotation in Fig. 1, to sow a maize crop and move from the Fallow 0 node to the Maize node in Fig. 1, the following rules need to be met: the date must be between September 15th and October 15th; the combined stored water in the soil and unallocated water in the farm storage must be greater than $4 \mathrm{ML}$ for each hectare of the field to be sown; the existing area sown to summer grain (maize or sorghum) should be less than $50 \%$ of the total farm area; days elapsed since the last harvest event must be greater than 14 days; and machinery must be available to sow the proposed area. Similar rules exist for an alternative crop, in this case sorghum, except the sowing window begins on October 16th, the close of the maize sowing window. Priority then is given to maize over sorghum for fields that are attempting to sow a summer grain (i.e. fields with current state Fallow 0 ). If a season exhibits no sowing opportunity it may be possible to by-pass a crop node. Again using the example in Fig. 1, if after the sorghum sowing window has closed and sorghum was not able to be sown the field's state will change from the Fallow 0 node to the Fallow 1 node.

\subsubsection{Description of model irrigation infrastructure and its management}

APSFarm has the provision to specify one or more sources of farm water for irrigation via multiple instances of APSIM's WaterSupply module (Gaydon and Lisson, 2005). Each instance can be configured to be a water source such as a bore, river, or sump capturing off-farm overland flow, or configured to be an open water storage which maintains an available pool of water for irrigation. APSIM achieves this by executing daily processes such as the capture of rainfall, accumulating on-farm runoff from fields, and losses due to evaporation and seepage. Depending on the physical farm being modelled each source of water can directly irrigate fields or transfer irrigation water between sources via open channels, which incur losses due to evaporation and seepage, e.g. the filling of open water storages from a bore.

The timing of irrigation events is determined on a daily basis by the difference between each field's modelled soil water deficit and a predetermined crop-specific threshold. When a field's extractable soil water falls below this threshold for the crop it currently has growing, the field is flagged as in need of irrigation. Then provided that: (a) there is sufficient unallocated irrigation water; (b) farm pumps are not already in operation and hence there is sufficient pumping capacity; and (c) the appropriate irrigation equipment is available; water is pumped from the storages into the fields and pumping costs and transfer losses are calculated.

It is common for different crops grown concurrently to have different priorities with respect to access to limited farm irrigation water. For example a high value crop with high water use such as cotton will have a higher priority for irrigation than a lower value crop such as sorghum. To capture these priorities in the model the management of farm irrigation water is based on a conceptual allocation model, which tracks the anticipated crop water requirements. To demonstrate, consider Fig. 2 which shows an example time series of the daily available water (solid line), and allocated water (dashed line) from a case study farm. When the model con- 

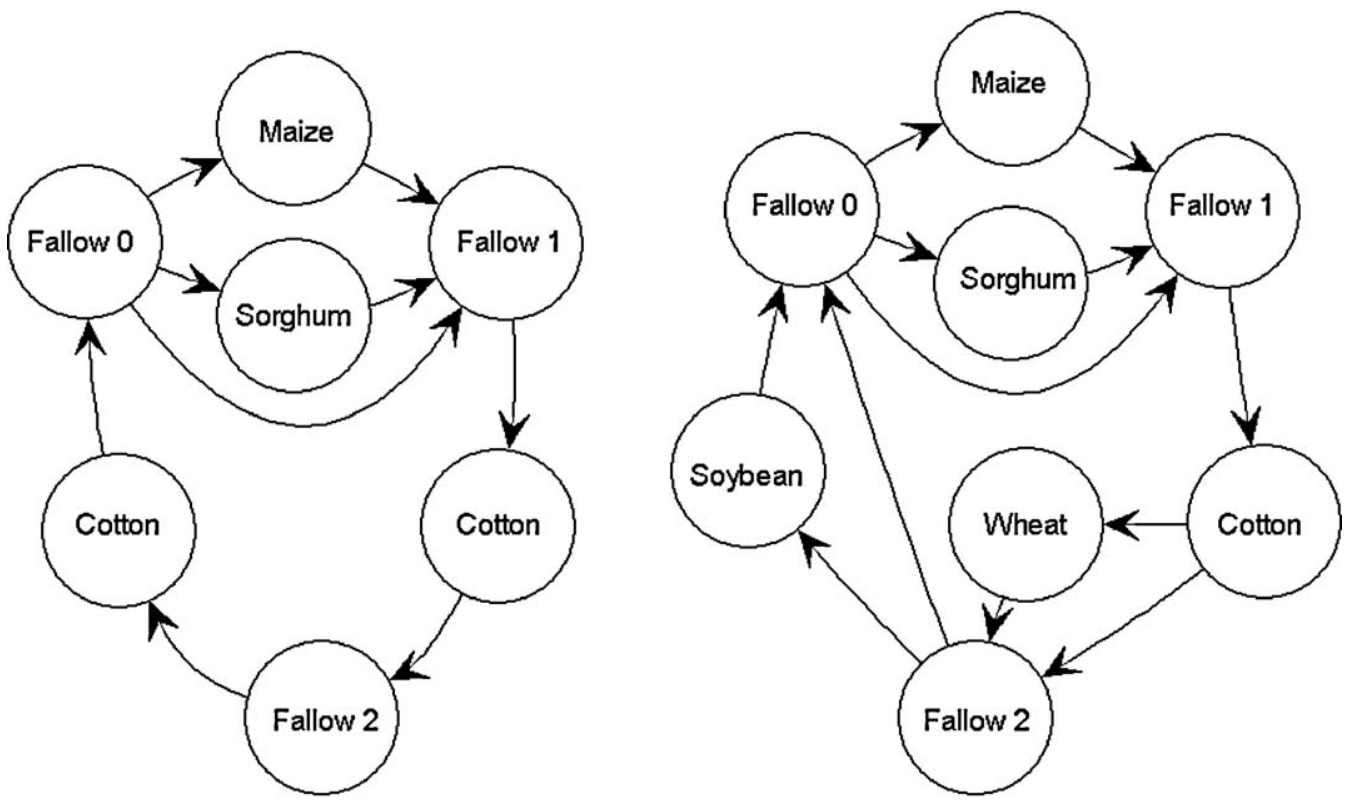

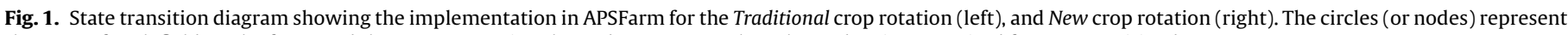
the state of each field on the farm, and the arcs connecting the nodes represent the rules and actions required for any transition between states.

siders sowing an irrigated crop in a field, it tests that the total unallocated farm water is greater than a nominated crop specific threshold (ML/ha) multiplied by the area of the field to be sown (ha). This amount (ML) is the farmer's estimate of the total stored water required to grow this crop. However, due to the seasonal variability of rainfall, crop water use and soil evaporation, this threshold is not intended as an accurate estimate of the irrigation water requirements of each crop but is related to the managers risk attitude. For example, too high a threshold will limit the area sown and could incur an opportunity cost of missed production, too low a threshold could result in an economic loss due to low yields from crops that are stressed due to a lack of irrigation water.

Should there be sufficient unallocated water available then the model will proceed with sowing and that amount is added to the allocated pool, as shown by the Sowing events in Fig. 2, which then becomes unavailable to other crops. For a high value and high water use crop such as cotton this threshold will be considerably higher than for a lower value lower water consumption crop such as sorghum. This prevents a low value crop from consuming irrigation water that would otherwise be needed by the high value crop, and is similar to how a farm manages the competing irrigation pri-

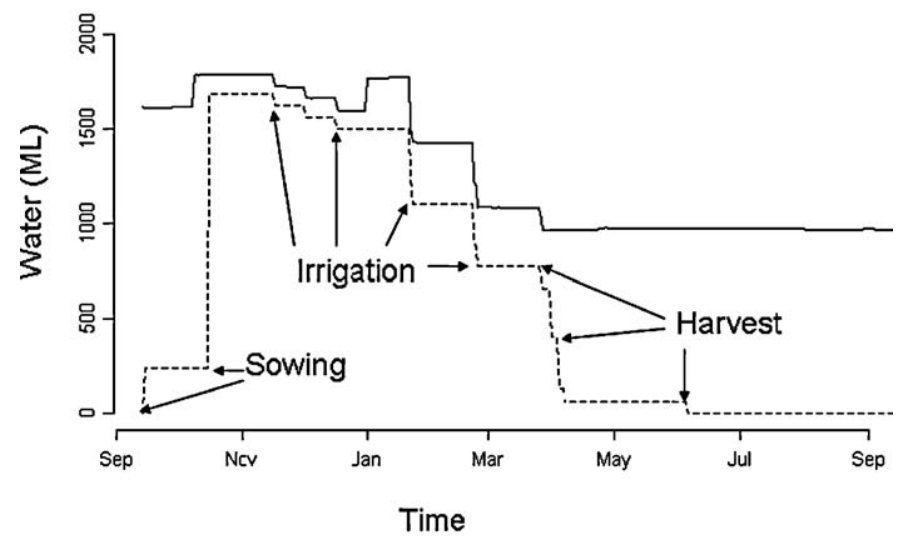

Fig. 2. Simulated time series of available water in farm storages (solid line), and the conceptual model of allocated storage water (dashed line), i.e. the estimate of the water required for the remainder of the season. orities between crops. When a crop is harvested, any unused water for that crop is released and the allocated series updated.

In the model, on farm water-storage levels change dynamically through the season as losses occur due to evaporation, seepage and irrigation events, while inflows occur from intercepted rainfall, captured runoff from fields, or the capture in a sump of ephemeral overland flow. To generate a historical time series of overland flow a simple sub-catchment model was developed and calibrated against farmer's estimates, i.e. a multi-year simulation was calibrated to reproduce the farm manager's records. When daily run-off is greater than some critical value the sump is assumed to be full and water is pumped into the storage. The calibrated model was then used to generate a full historical record of the same length as the historical climate series. This technique maintains both the necessary correlation between the overland flow events and historical climate data and the temporal correlation within the overland flow time-series.

\subsubsection{Economic analysis}

The third component in APSFarm is an economic module, though here its implementation differs to that described in de Voil et al. (2009). Here the economic analysis was conducted post simulation, which allowed us to explore a range of price scenarios without the need to re-run the simulation.

Variable costs and commodity prices for each enterprise are obtained from interviews with collaborating farmers. The total farm gross margin $\left(G M_{\text {farm }}\right)$ for each season is the aggregate of all field gross margins $\left(G M_{\text {field }}\right)$ for that season:

$G M_{\text {farm }}=\sum G M_{\text {field }}$

where $G M_{\text {field }}$ is given by the simulated yield $(Y)$ multiplied by the expected on-farm crop price $(P)$ and the field area $(A)$ less costs due to: cartage $(C)$; levies $(L)$; harvesting $(H)$; irrigation $(I)$; sowing $(S)$; fallow management $(F)$, and nitrogen fertilisation $(N)$, i.e.

$G M_{\text {field }}=Y P A-(C+L+H+I+S+F+N)$

Fallow costs are calculated by simulating the number of weed germination events multiplied by herbicide application costs. Weed events occur after a significant rainfall, and when there is 
enough soil water in the top soil layer for the weeds to establish and develop.

The seasonal crop nitrogen requirements are modelled by APSIM's nitrogen module SOILN (Probert et al., 1997). The fertiliser is applied at sowing, at a rate calculated from the difference between the crop nitrogen requirements as specified by the collaborating farmers and soil nitrogen availability at sowing. The rate of $\mathrm{N}$ fertilisation then can vary between seasons, and across fields due to their different cropping history. Resulting distributions of applied nitrogen were validated with the participating farmer.

Harvest costs for a field depend on the type of crop and its yield and the area of the field. The harvest cost $(H)$ for each field is equal to the fuel spent $(f)$ plus machinery variable costs $(m)$ to harvest the field. This is typically calculated as the hourly rate $(h)$ for a contract header, multiplied by its work rate $(W R)$ and the field's area $(A)$ as:

$H=f+m$

$m=h \times W R \times A$

Machinery work rates are constant $\left(W R_{U}\right.$ and $\left.W R_{L}\right)$ when crop yields are greater and less than upper $\left(Y_{U}\right)$ and lower $\left(Y_{L}\right)$ limits. It is assumed a linear relationship between the two. These bifurcation points are specified by the farm or contract harvester and are expressed in equation form as:

$W R=\left\{\begin{array}{l}W R_{U}, \quad Y>Y_{U} \\ \frac{W R_{U}-W R_{L}}{Y_{U}-Y_{L}}\left(Y-Y_{L}\right)+W R_{L}, \quad Y_{L} \leq Y \leq Y_{U} \\ W R_{L}, \quad Y<Y_{L}\end{array}\right.$

Similarly, the cost of fuel $(f)$ in harvesting a field is given by:

$f=\left\{\begin{array}{l}f_{U}, \quad Y>Y_{u} \\ \frac{f_{U}-f_{L}}{Y_{U}-Y_{L}}\left(Y-f_{L}\right)+f_{L}, \quad Y_{L} \leq Y \leq Y_{U} \\ f_{L}, \quad Y<Y_{L}\end{array}\right.$

\subsection{Description of case-study farm}

The model was applied to a case study of an irrigated broadacre cropping enterprise near Dalby, Queensland, Australia. The farm manager was interested to understand the economic and environmental implications from implementing a New more diversified crop rotation, including fewer cotton crops, introducing legumes and more cereal crops, compared to the local Traditional cotton dominated rotation. Key criteria to adopt the New crop rotation would be that the profit/risk profile of the farm business would not change, and that the increased diversification in the rotation would introduce environmental benefits. Fig. 1 shows the directed graphs of the two rotations, and Table 1 presents the sowing rules for each crop.

The modelled farm has three on-farm water storages (A, B and C) two with a $500 \mathrm{ML}$ capacity (A and B), and a $300 \mathrm{ML}$ storage (C). The total cropping area for the farm is 780 ha with 13 by 60 ha management units or fields. Due to constraints on irrigation channels, each water-storage can only supply irrigation water and collect runoff water from fixed areas of the farm; 240 ha ( 4 fields), 300 ha ( 5 fields) and 240 ha ( 4 fields), respectively. However it is possible to transfer water between storages when necessary. The delivery of irrigation water to the fields is restricted to the pumping capacities listed in Table 2. The average cost of supplying water to the field is ca. AU \$45/ML. This includes pumping from sumps into storages, transfers between storages if required, transfers from storages to fields, and the return of tail water to the water storages. In addition to the water storages, the farm has five bores with a combined allocation of $610 \mathrm{ML} /$ year and the possibility to carry-over $50 \%$ of any unused
Table 1

Sowing rules for each crop.

\begin{tabular}{ll}
\hline Crop & Sowing rules \\
\hline Maize & Date between September 15 and October 15 \\
& Combined stored water in soil and water storage $\geq 4 \mathrm{ML} / \mathrm{ha}$ \\
& Proportion of existing farm area sown to Maize or Sorghum $\leq 50 \%$ \\
& Days since last harvest $>14$ days \\
& Machinery available \\
Sorghum & Date between October 16 and January 14 \\
& Combined stored water in soil and water storage $\geq 0 \mathrm{ML} / \mathrm{ha}$ \\
& Sum of last 4 days rain $\geq 25$ mm \\
& Proportion of existing farm area sown to Maize or Sorghum $\leq 50 \%$ \\
& Days since last harvest $>14$ days \\
& Machinery available \\
& Date between October 16 and November 15 \\
& Combined stored water in soil and water storage $\geq 4 \mathrm{ML} / \mathrm{ha}$ \\
Cotton & Proportion of existing farm area sown to cotton $\leq 50 \%$ \\
& Days since last harvest $>14$ days \\
& Machinery available \\
& Date between April 16 and July 1 \\
& Combined stored water in soil and water storage $\geq 0 \mathrm{ML} / \mathrm{ha}$ \\
& Sum of last 4 days rain $\geq 10$ \\
& Soil water $\geq 100$ mm \\
Wheat & Days since last harvest $>14$ days \\
& Machinery available \\
Date between December 1 and January 15 \\
Combined stored water in soil and water storage $\geq 3 \mathrm{ML} / \mathrm{ha}$ \\
\\
Days since last harvest $>14$ days \\
Machinery available \\
\hline
\end{tabular}

allocation into the following year. Water from the bores can be supplied to all fields, though at a considerably reduced flow rate (i.e. $0.5 \mathrm{ML} / \mathrm{h}$ ), hence time becomes a limiting resource when irrigating from bores, and the cost of water applied to the field is higher ca. AU\$110/ML.

This particular farmer, as most irrigation farmers in the region, uses a furrow irrigation system which involves applying water at the top of a furrow between rows of plants and allowing it to flow down to the end of the row via gravity. The system is inherently inefficient (Smith et al., 2005) as more water than required to bring the soils to field capacity is pumped from the storage, and excess run-off is returned as tail water with an associated cost. To capture this inefficiency, an additional $25 \%$ more water than what is required to fill the profile is pumped (collaborating farmer and consulting irrigation engineer, pers. comm., 2008). Evaporation and seepage losses were assumed to be $5 \%$ during transfer in the channels. The values for transfer losses and irrigation efficiency were determined in consultation with the farmer and irrigation engineers. Table 3 presents the crop irrigation thresholds provided by the farmer (with corresponding values given in Allen et al., 1998 [FAO 56]); and the anticipated seasonal irrigation requirements for each crop. This particular farmer does not irrigate wheat and, therefore, there are no corresponding irrigation parameters for this crop. The zero anticipated irrigation requirements for sorghum indicates that this farmer does not reserve any water for irrigating sorghum crops at sowing. However sorghum may still be irrigated if there is surplus water that is unallocated to other higher priority crops.

The model was run using long term patched historical climate records (Jeffrey et al., 2001) from 1890 to 2008 for Dalby, Queensland. The overland flow sub-model was calibrated to an average annual overland flow of approximately $700 \mathrm{ML} /$ year, with a minimum of 0 and a maximum of $1350 \mathrm{ML} /$ year using the past 30 years of climate data. The aggregate variable costs and commodity prices for each enterprise are presented in Table 4 . Table 5 presents the farmer's specified values for the parameters of Eqs. (5) and (6).

\section{Results}

Fig. 3a and $\mathrm{b}$ shows the distributions of the simulated yields for each crop across all the fields and simulated years, i.e. farm yields. 
Table 2

Parameters describing the on farm water-storages.

\begin{tabular}{|c|c|c|c|c|c|}
\hline Water storage & Capacity (ML) & Surface area (ha) & Cropping area (ha) & In-flow rate $(\mathrm{ML} / \mathrm{h})$ & Out-flow rate $(\mathrm{ML} / \mathrm{h})$ \\
\hline A & 500 & 12 & 240 & 7 & 1.75 \\
\hline B & 500 & 11 & 300 & 8.5 & 2 \\
\hline C & 300 & 8 & 240 & 5.3 & 1.5 \\
\hline
\end{tabular}

Table 3

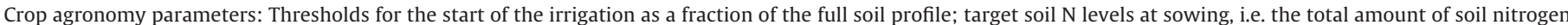
required at sowing.

\begin{tabular}{|c|c|c|c|}
\hline Crop & Fraction of full profile and FAO 56 recommendation & Anticipated seasonal irrigation requirements (ML/ha) & Soil $\mathrm{N}$ at sowing $(\mathrm{kg} / \mathrm{ha})$ \\
\hline Maize & $40 \%(55 \%)$ & 4 & 240 \\
\hline Sorghum & $50 \%(55 \%)$ & 0 & 220 \\
\hline Cotton (sown at $2 \mathrm{~m}$ ) & $40 \%(65 \%)$ & 4 & 140 \\
\hline Wheat & Not applicable & Not applicable & 160 \\
\hline Soybean & $70 \%(50 \%)$ & 3 & 0 \\
\hline
\end{tabular}
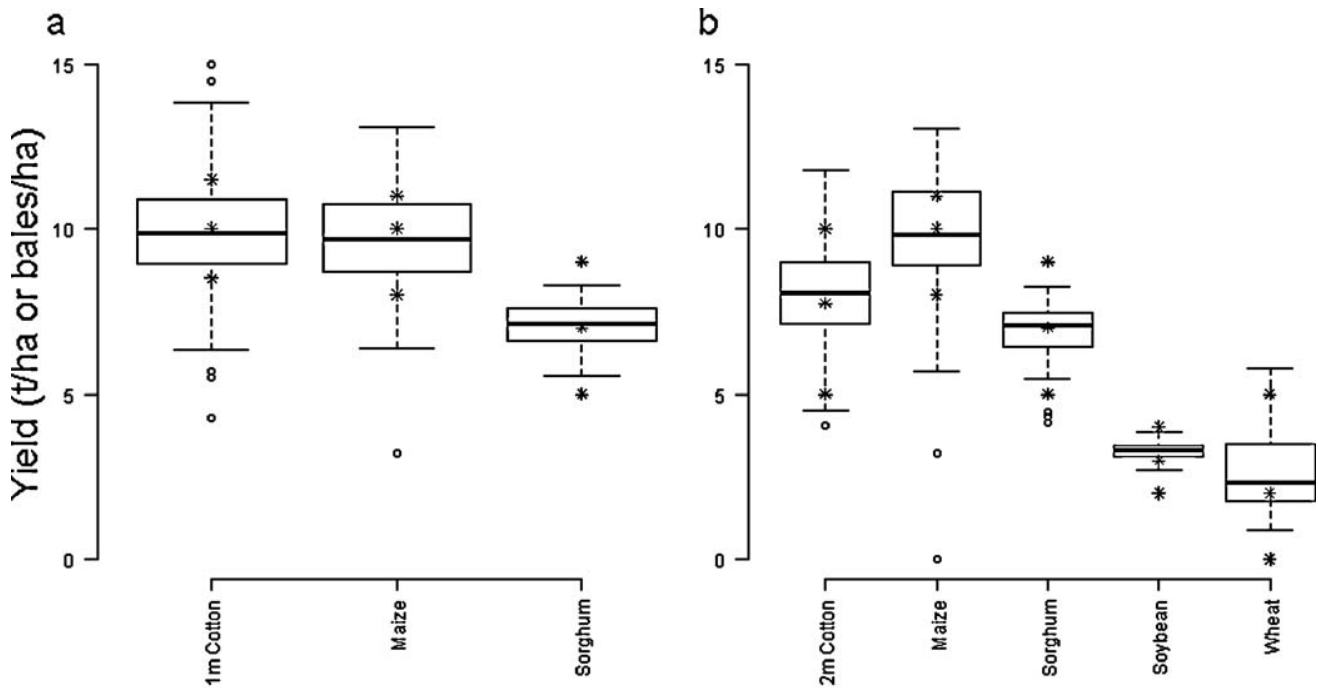

Activity

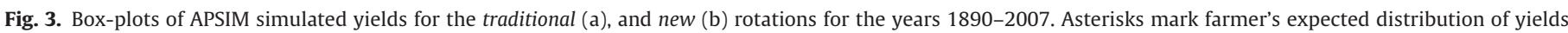
(maximum, median and minimum) for each crop. The small circles are yield outliers (i.e. yields that are more extreme than 1.5 times the Inter Quartile Ratio).

Table 4

Summarised variable cost and expected price for each crop activity. Costs are negative and fertiliser is not applied to soybean. Cotton yield is measured in bales (ba) all other crops are measured in tonnes $(\mathrm{t})$.

\begin{tabular}{lll}
\hline Description & Price/cost & Units \\
\hline Cotton price & 500.00 & AU\$/ba \\
Cotton seed sold (31\% @ 125/tonne) & 88.31 & AU\$/ba \\
Cotton harvest costs & -81.93 & AU\$/ba \\
1 m cotton sowing costs & -780.73 & AU\$/ha \\
2 m cotton sowing costs & -655.92 & AU\$/ha \\
Maize price & 250.00 & AU\$/t \\
Maize harvest cost & -13.50 & AU\$/t \\
Maize sowing cost & -344.71 & AU\$/ha \\
Sorghum price & 200 & AU\$/t \\
Sorghum harvest cost & -32.40 & AU\$/t \\
Sorghum sowing cost & -222.85 & AU\$/ha \\
Soybean price & 450.00 & AU\$/t \\
Soybean harvest cost & -29.50 & AU\$/t \\
Soybean sowing cost & -206.98 & AU\$/ha \\
Wheat price & 300.00 & AU\$/t \\
Wheat harvest cost & -33.40 & AU\$/t \\
Wheat sowing cost & -128.10 & AU\$/ha \\
Fuel & -1.30 & AU\$/L \\
Nitrogen fertiliser & -1.50 & AU\$/kg \\
Herbicide application & -22.99 & AU\$/weed event/ha \\
\hline
\end{tabular}

The asterisks in Fig. 3 indicate the highest, most likely and lowest yields for each crop as per farmer's experience (ca. 30 years). The most likely yields achieved by the farmer were reproduced well by APSFarm. Though, APSfarm simulated higher variability in yields than that suggested by the farmer, particularly for cotton and maize (i.e. range between minimum and maximum values in the boxplots from Fig. 3a and b). Interestingly, the farmer confirmed that the variability shown by the model might be a better representation of the real variability over the simulated climate series (i.e. 1900-2007). Therefore this discrepancy was not considered to be an important issue by the researchers or by the participating farmer who was confident that the model produced a fair representation of his business, and that the model would be useful to explore options to improve the farming system. The difference in simulated

Table 5

Case study specific parameters for Eqs. (5) and (6). Cotton yield is measured in bales (ba) all other crops are measured in tonnes $(t)$.

\begin{tabular}{llllll}
\hline Parameter & Cotton & Maize & Sorghum & Wheat & Soybean \\
\hline$Y_{L}$ & $3.2(\mathrm{ba} / \mathrm{ha})$ & $3.5(\mathrm{t} / \mathrm{ha})$ & $3.5(\mathrm{t} / \mathrm{ha})$ & $2.5(\mathrm{t} / \mathrm{ha})$ & $1(\mathrm{t} / \mathrm{ha})$ \\
$Y_{U}$ & $8.75(\mathrm{ba} / \mathrm{ha})$ & $11(\mathrm{t} / \mathrm{ha})$ & $8(\mathrm{t} / \mathrm{ha})$ & $5(\mathrm{t} / \mathrm{ha})$ & $3(\mathrm{t} / \mathrm{ha})$ \\
$W R_{L}$ & $1.6(\mathrm{ha} / \mathrm{h})$ & $4(\mathrm{ha} / \mathrm{h})$ & $6(\mathrm{ha} / \mathrm{h})$ & $6(\mathrm{ha} / \mathrm{h})$ & $4.5(\mathrm{ha} / \mathrm{h})$ \\
$W R_{U}$ & $0.7(\mathrm{ha} / \mathrm{h})$ & $1.5(\mathrm{ha} / \mathrm{h})$ & $3.75(\mathrm{ha} / \mathrm{h})$ & $3.75(\mathrm{ha} / \mathrm{h})$ & $2(\mathrm{ha} / \mathrm{h})$ \\
$f_{L}$ & $25.5(\mathrm{~L} / \mathrm{ha})$ & $12.1(\mathrm{~L} / \mathrm{ha})$ & $8.1(\mathrm{~L} / \mathrm{ha})$ & $8.1(\mathrm{~L} / \mathrm{ha})$ & $10.8(\mathrm{~L} / \mathrm{ha})$ \\
$f_{U}$ & $58.2(\mathrm{~L} / \mathrm{ha})$ & $32.3(\mathrm{~L} / \mathrm{ha})$ & $12.9(\mathrm{~L} / \mathrm{ha})$ & $12.9(\mathrm{~L} / \mathrm{ha})$ & $24.3(\mathrm{~L} / \mathrm{ha})$ \\
\hline
\end{tabular}



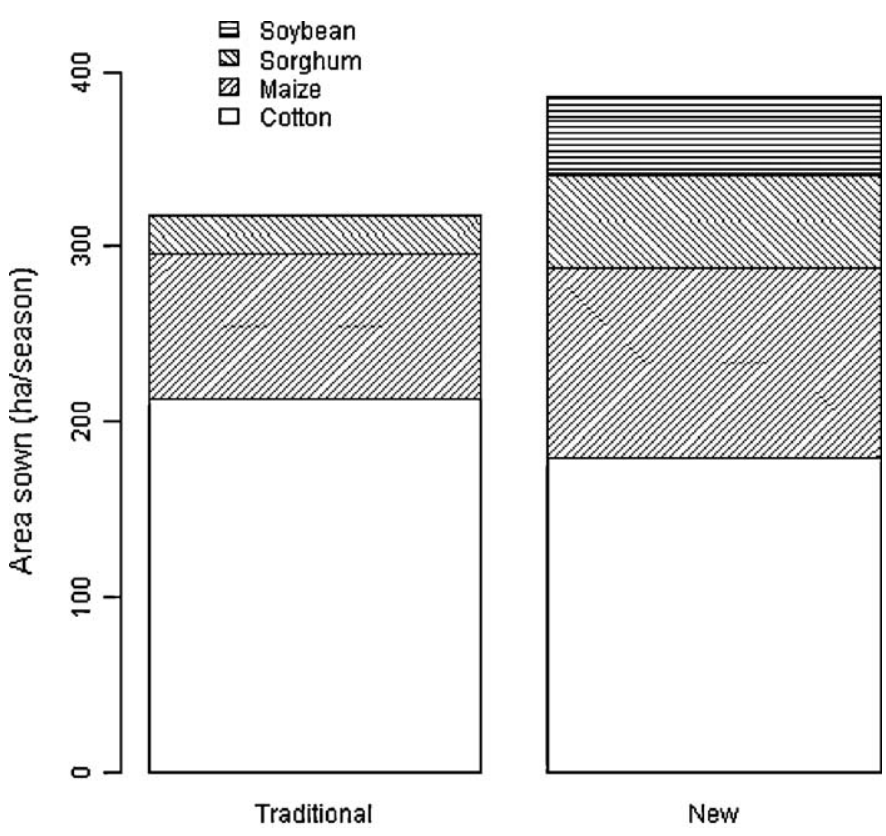

Fig. 4. Simulated sowing areas for summer crops (i.e. excludes wheat) in the traditional and new rotation (results from the last 10 years of simulation are shown here).

cotton yield between the two rotations was explained by the two different row configurations, i.e. $1 \mathrm{~m}$ spaced rows in the traditional, compared to the $2 \mathrm{~m}$ apart in the new rotation. The participating farmer was confident that the model produced a fair representation of his business, and that the model would be a useful tool to explore options to improve the farming system. The farmer also indicated that the model represented realistically the allocation of land across the alternative summer crop enterprises, both in the traditional and new rotations (Fig. 4). Compared to the traditional rotation, the new rotation on average had $16 \%$ less area dedicated to cotton; a $34 \%$ increase in the area dedicated to maize; a $145 \%$ increase in the area of sorghum; and introduced 46 ha of soybean, increasing the annual cropping area by ca. 69 ha. On average, the new rotation increased the cropping intensity from $41 \%$ to $50 \%$.
Fig. 5a and $\mathrm{b}$ shows the simulated distributions of applied irrigation water for both the traditional and new rotations, respectively. Wheat intentionally has no corresponding box to highlight that it is a rainfed crop and its main role in the rotation is to provide cover after the cotton crop. The amounts of applied irrigation water for each crop were in agreement with the farmer's experience, i.e. asterisk in Fig. 5. The reduction in the use of water by the cotton crop in the new rotation is because it is sown in a $2 \mathrm{~m}$ row configuration, compared to the $1 \mathrm{~m}$ configuration in the traditional rotation.

Fig. 6 shows the distributions of simulated gross margins for each individual crop in the traditional and new rotation. In both rotations cotton is clearly the most profitable crop, followed by maize and soybean. Wheat is the least profitable crop and in 2 out of 10 years it is likely that the farmer will lose some money. When the gross margins and total nitrogen use were aggregated to the whole farm level (Figs. 7 and 8), the new rotational system demonstrated to be more profitable (one-sided student's $t$-test, the $p$-value $=0.005$ ), with no increase in down-side risk, and on average required $12 \%$ less nitrogen than the traditional rotation, i.e. $17 \mathrm{~kg}$ $\mathrm{N} /$ ha less nitrogen.

\section{Discussion}

Farming is complex and multi-dimensional. Irrespective of the level of resource endowment, e.g. highly productive or marginal; scale (e.g. large or small scale holders); production orientation (e.g. commercial or subsistence), farming embodies the management of complicated farms with limited access to resources (e.g. cash, land, labour, water for irrigation), limited information and knowledge; limited time to make decisions; operating in highly variable and uncertain environments; having competing objectives; and with particular attitudes to risk and change. In the face of complexity, we argue there is an important role for integrative systems modelling tools that are able to describe and summarise key features and interactions in the system, i.e. a simplified though still relevant representation of the farm business. Once this is achieved these tools can be used to generate relevant information that inform discussions between researchers and farmers and facilitate learning about opportunities to reduce impacts or capture opportunities emerging from the ever changing conditions affecting the business. We propose that this can be achieved by combining bio-physical

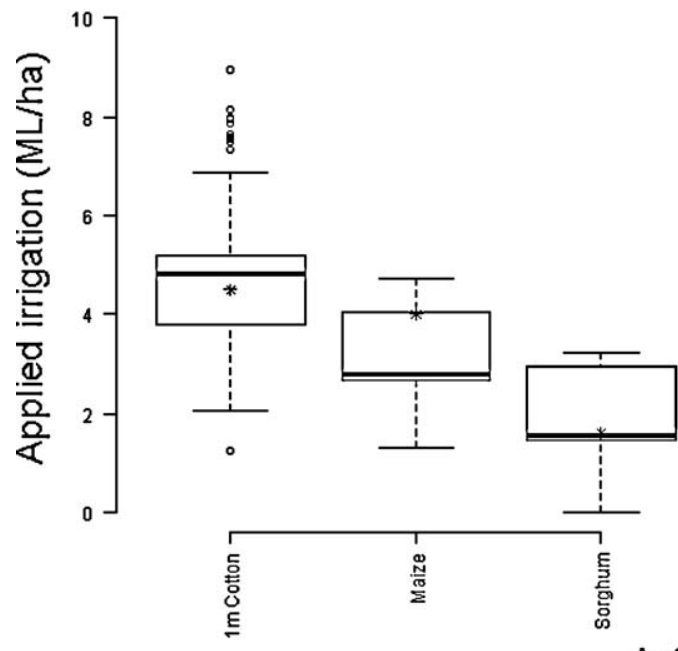

b

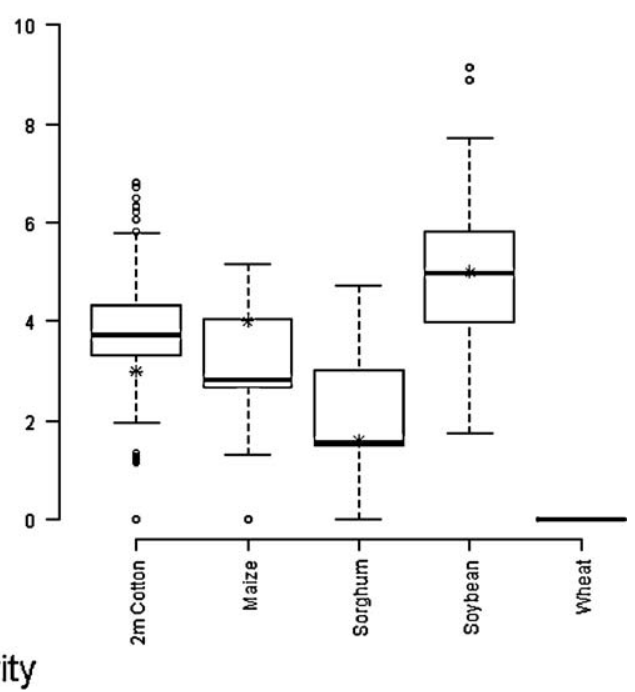

Fig. 5. Simulated applied irrigation ( $\mathrm{ML} / \mathrm{ha}$ ) for each crop in the traditional (a) and new (b) crop rotation. The wheat crop in the new rotation is rainfed. 


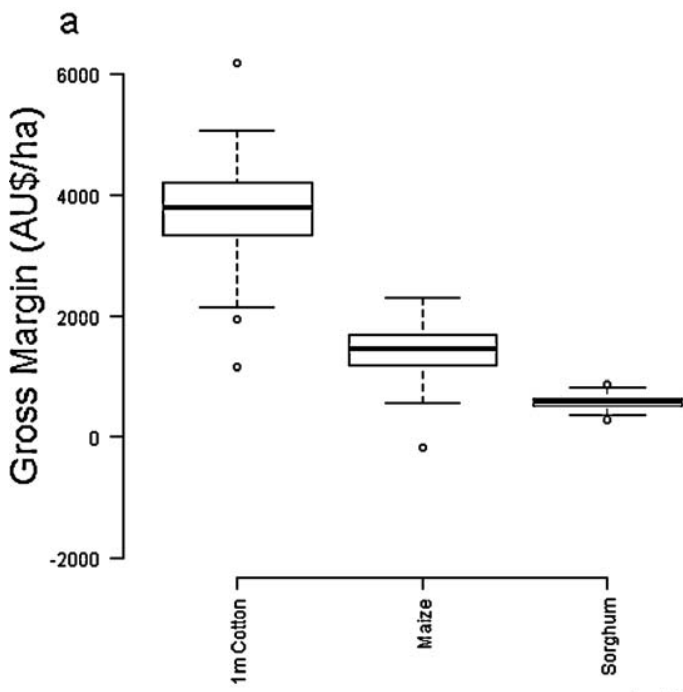

b

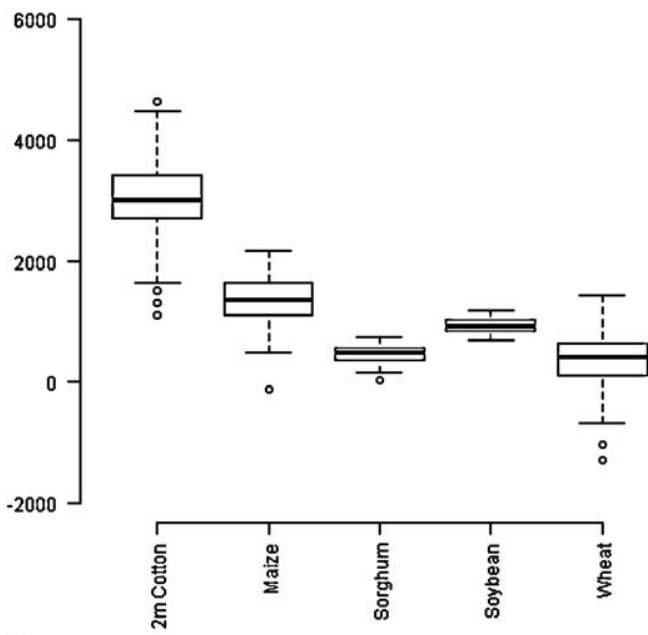

Fig. 6. Simulated gross margins ( $\$ /$ ha) for each crop for the traditional (a) and new (b) rotations.

and socio-economic approaches in a meaningful 2-way partnership with farmers, where topics of shared interest are identified and opportunities for improving practices, tactics and strategies are discussed at a range of interrelated scales - the plant, the field and the whole farm business.

In this paper, we describe a problem common to many Australian irrigation growers where regulatory changes and drought have seen the reduction of water availability and a consequent price increase, forcing growers into an increasing reliance on highly variable in-crop rainfall. The development and application of an integrative and interdisciplinary participatory modelling framework has been invaluable to help explore such complex farming systems design questions.

\subsection{Performance of APSFarm}

The APSFarm participatory modelling framework was developed to quantify whole farm dynamics and interactions resulting

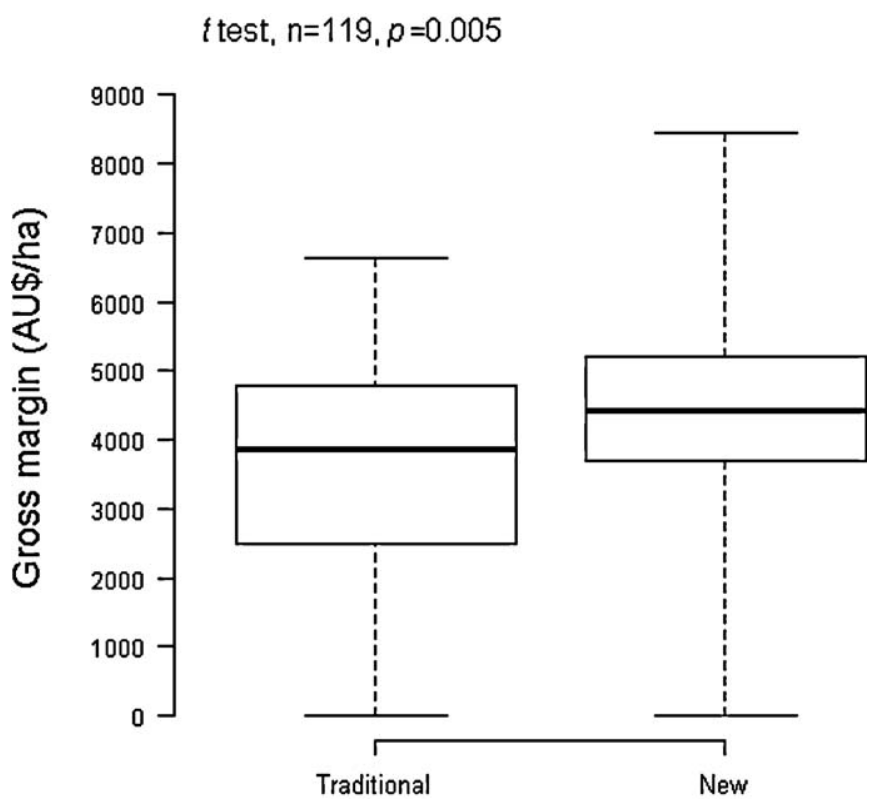

Fig. 7. Simulated whole farm gross margins for the traditional and new rotations. Distributions are significantly different (one-sided student's $t$-test $p$-value is 0.005 ). from the alternative allocation of limited resources (i.e. land, finances, water, labour, machinery, livestock) in response to present or expected changes (e.g. climate, markets and policy). APSFarm is an integrative tool in the sense that it not only accounts for the biophysics of crop growth and production but also incorporates economic and social aspects affecting the allocation of limited resources at the whole farm level. We also claim that the development and application of APSFarm involved a range of related disciplines including, computational sciences, economics, agronomy, crop sciences, engineering, communication, and social sciences.

The need for integrative and multidisciplinary systems modelling approaches has been long recognised (Gough et al., 1998), and since, a large number of approaches have been developed,

$$
\text { t test, } n_{T}=624, n_{N}=891,0<0.0001
$$

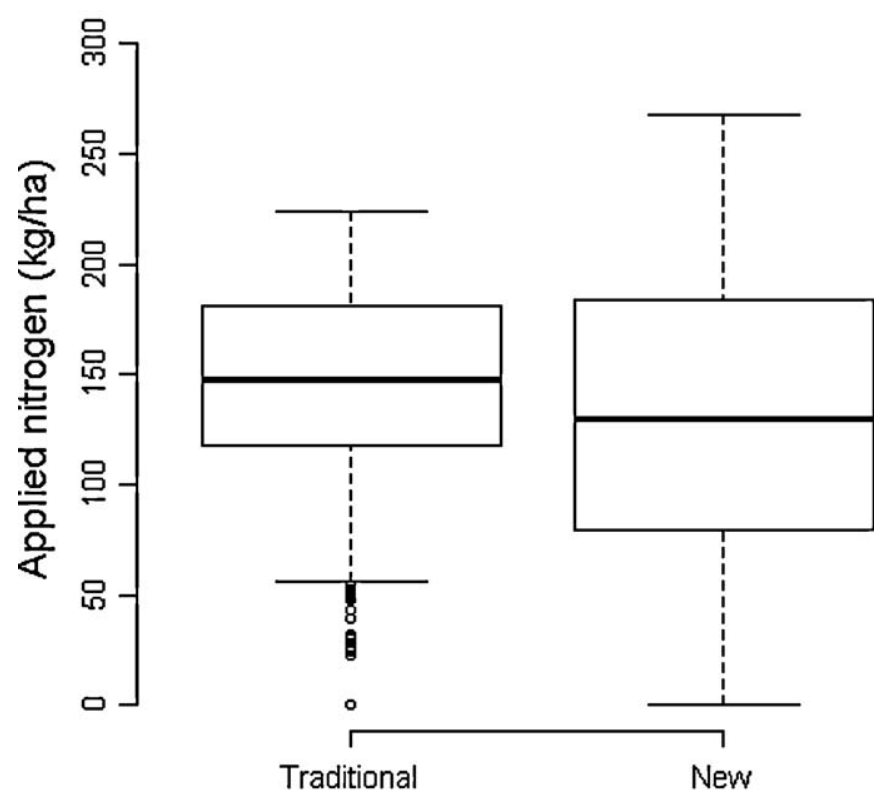

Fig. 8. Total nitrogen applied ( $\mathrm{kg} \mathrm{N} / \mathrm{ha}$ ) in the traditional and new rotation. Distributions are significantly different (one-sided student's $t$-test $p$-value $<0.001$ ). 
e.g. decision support systems in pastoral farm businesses (Herrero et al., 1999); in the evaluation of long-term economic, and environmental performance of dairy farms (Rotz et al., 1989); as well as in whole farm planning in dryland cropping systems (Kingwell and Pannell, 1987). During the mid 1990s, in an attempt to quantify "sustainability" in farming systems, Hansen and Jones (1996) concluded that "... the requirement for comprehensive and realistic farm simulation tools currently limits application of the proposed approach,... they do not integrate models of crop and animal production, environmental degradation, economic processes and farmer production and consumption decisions...". Ten years later Janssen and vanittersum (2007) reviewed 48 applications of bio-economic farm models covering arable, mixed grain and grazing, livestock, dairy, and vegetable industry sectors. Out of the 48 models only two could be characterised as dynamic, mechanistic and stochastic, most were static equilibrium models using some kind of optimisation algorithm to identify optimum courses of action or allocation of resources.

Optimisation studies rely on a number of assumptions, to name a few: goals must be well defined in advance and the operational environment must be stable (Klein, 2001). Unfortunately, both are often not the case, which is why in reality decision makers will usually be "satisficers" rather than optimisers (Klein, 2001), which mean that they will select the first course of action that appears to be successful. In most cases farmer decisions are driven by multiple and often conflicting objectives of which profit optimisation might be only one of them, while the operational environment changes almost on a daily basis. An alternative approach is the use of dynamic-functional-stochastic whole farm systems models in conjunction with participatory research to generate new information that is relevant to the participating farmers, information that when reflected upon can create new experiential knowledge that increases the capacity of the participating farmers to make better decisions.

\subsection{Feedback from the case study farm}

In our case study, the participating farmer wanted to understand the economic implications from implementing a New more diversified crop rotation, including fewer cotton crops, introducing legumes and more cereal crops, compared to the local Traditional cotton-dominated rotation. Results indicated that the more diversified farming system was more profitable than the traditional farming system (Figs. 6 and 7). After these results were discussed with the farmer he felt more confident that the change in rotation was a good business decision, and that the new rotation gave him more flexibility for marketing due to the increase in crop diversity. In the process we found that it was important for the farmers to understand the capacity of the model to represent his farming system, and that even though its performance was not perfect (Figs. 3 and 5), the modelling tool allowed the group to run quick, inexpensive and realistic desktop analyses of the potential impacts of changing the farming system.

\section{Conclusions}

Here we described APSFarm, a new whole farm simulation model and shown how it can be configured to simulate and irrigated farm business. We have also provided an example of how this model can be used in close interaction between farmers and researchers to test and learn about improved farm business tactics and strategies. The use of the model in partnership with farmers allows for better informed discussions on the performance of complicated farm businesses. Technologically, APSFarm proved to be a solid performer and a good alternative to static equilibrium models, with the additional benefit of allowing for dynamically integrating the multiple dimensions of highly complicated irrigated farm businesses.

\section{Acknowledgments}

This study was funded by: the Queensland Government; Grains Research and Development Corporation (GRDC); Cotton Research and Development Corporation (CRDC); the National Program for Sustainable Irrigation (NPSI); and the Cotton Catchment Communities Cooperative Research Centre (Cotton CRC). The authors acknowledge the valuable contribution made by the Darling Downs farmer who volunteered his time to participate in this study. We also thank the two anonymous reviewers for their valuable comments.

\section{References}

Allen, R.G., Pereira, L.S., Raes, D., Smith, M., 1998. Crop evapotranspiration - guidelines for computing crop water requirements, Irrigation and Drainage Paper No. 56 , FAO, Rome, Italy.

Brennan, L.E., Lisson, S.N., Poulton, P.L., Carberry, P.S., Bristow, K.L., Khan, S., 2008 A farm-scale, bio-economic model for assessing investments in recycled water for irrigation. Aust. J. Agric. Res. 59, 1035-1048.

Dillon, J.L., 1965. Farm management in Australia as an academic discipline. Rev. Market. Agric. Econ. 33, 175-189.

de Voil, P., Rodriguez, D., Power, B., 2009. Simulation of whole farm management decisions. In: Anderssen, R.S., Braddock, R.D., Newham, L.T.H. (Eds.), 18th World IMACS Congress and MODSIM09 International Congress on Modelling and Simulation. Modelling and Simulation Society of Australia and New Zealand and International Association for Mathematics and Computers in Simulation, July 2009, pp. 2377-2383. ISBN:978-0-9758400-7-8, www.mssanz.org.au/modsim09/B3/deVoil.pdf.

Gaydon, D.S., Lisson, S.N., 2005. APSIM WaterSupply. In: Inman-Bamber, G., Attard S. (Eds.), "Inventory of Australian Software tools for Best Use of Water On-Farm" - Final Report for Project 3.08, CRC for Irrigation Futures.

Gough, C., Catells, N., Funtowicz, S., 1998. Integrated assessment: an emerging methodology for complex issues. Environ. Model. Assess. 3, 19-29.

Hansen, J.W., Jones, J.W., 1996. A systems framework for characterising farm sustainability. Agric. Syst. 51, 185-201.

Herrero, M., Fawcett, R.H., Dent, J.B., 1999. Bio-economic evaluation of dairy farm management scenarios using integrated simulation and multiple-criteria models. Agric. Syst. 62, 169-188.

Howden, S.M., Soussana, J.F., Tubiello, F.N., Chetri, N., Dunlop, M., Meinke, H., 2007. Adapting agriculture to climate change. PNAS 104, 19691-19696.

Jeffrey, S.J., Carter, J.O., Moodie, K.M., Beswick, A.R., 2001. Using spatial interpolation to construct a comprehensive archive of Australian climate data. Environ. Model. Softw. 16 (4), 309-330.

Janssen, S., vanIttersum, M.K., 2007. Assessing farm innovation and responses to policies: a review of bio-economic farm models. Agric. Syst. 94, 622-636.

Keating, B.A., Carberry, P.S., Hammer, G.L., Probert, M.E., Robertson, M.J., Holzworth, D., Huth, N.I., Hargreaves, J.N.G., Meinke, H., Hochman, Z., McLean, G., Verburg, K., Snow, V., Dimes, J.P., Silburn, M., Wang, E., Brown, S., Bristow, K.L., Asseng, S., Chapman, S., McCown, R.L., Freebairn, D.M., Smith, C.J., 2003. An overview of APSIM, a model designed for farming systems simulation. Eur. J. Agron. 18 (3-4), 267-288.

Kingwell, R.S., Pannell, D.J. (Eds.), 1987. MIDAS: A Bioeconomic Model of a Dryland Farm System. Pudoc, Wageningen.

Klein, G., 2001. The fiction of optimisation. In: Gigerenzer, G., Selten, R. (Eds.) Bounded rationality. The adaptive Toolbox, Dahlem Workshop Reports. MIT Press, Cambridge.

McCown, R.L., 2002. Locating agricultural decision support systems in the problematic history and socio-technical complexity of 'models for management'. Agric. Syst. 74, 11-25.

McCown, R.L., Parton, K.A., 2006. Learning from the historical failure of farm management models to aid management practice. Part 2. Three systems approaches. Aust. J. Agric. Res. 57, 157-172.

McCown, R.L., Carberry, P.S., Hochman, Z., Dalgliesh, N.P., Foale, M.A., 2009. Reinventing model-based decision support with Australian dryland farmers. 1. Changing intervention concepts during 17 years of action research. Crop Pasture Sci. 60, 1017-1030.

Meinke, H., Hochman, Z., 2000. Using seasonal climate forecasts to manage dryland crops in northern Australia - Experiences from the 1997/198 seasons. In Hammer, G.L., Nicholls, N., Mitchell, C. (Eds.), Applications of Seasonal Climate Forecasting in Agriculture And Natural Ecosystems - The Australian Experience. Kluwer, pp. 149-165.

Meinke, H., Howden, M.S., Struik, P.C., Nelson, R., Rodriguez, D., Chapman, S.C., 2009 Adaptation science for agriculture and natural resource management - urgency and theoretical basis. Curr. Opin. Environ. Sust. 1, 69-76. 
Nelson, R.A., Holzworth, D.P., Hammer, G.L., Hayman, P.T., 2002. Infusing the use of seasonal climate forecasting into crop management practice in North East Australia using discussion support software. Agric. Syst. 74, 393-414.

Parry, M., Lowe, J., Hanson, C., 2009. Overshoot, adapt and recover. Nature 458, 1102-1103.

Probert, M.E., Dimes, J.P., Keating, B.A., Dalal, R.C., Strong, W.M., 1997. APSIM's water and nitrogen modules and simulation of the dynamics of water and nitrogen in fallow systems. Agric. Syst. 56, 1-28.

Reyenga, P.J., Howden, S.M., Meinke, H., McKeon, G.M., 1999. Modelling global change impacts on wheat cropping in south-east Queensland Australia. Environ. Model. Softw. 14, 297-306.
Rotz, C.A., Buckmaster, D.R., Mertens, D.R., Black, J.R., 1989. DAFOSYM: a dairy forage system model for evaluating technologies and management strategies in forage conservation. J. Dairy Sci. 72, 3050-3063.

Smith, R.J., Raine, S.R., Minkevich, J., 2005. Irrigation application efficiency and deep drainage potential under surface irrigated cotton. Agric. Water Manage. 71, 117-130.

Tittonell, P., vanWijk, M.T., Rufino, M.C., Vrugt, J.A., Giller, K.E., 2007. Analysing tradeoffs in resource and labour allocation by smallholder farmers using inverse modelling techniques: a case-study from Kakamega district, western Kenya. Agric. Syst. 95, 76-95 